\title{
The economic value of the wildlife trade in Vietnam
}

\author{
Pham Thu Thuy', Tran Yen Ly², Nguyen Thi Kieu Nuong³, Tang Thi Kim Hong ${ }^{3}$ and Dang Hai Phuong ${ }^{3}$
}

\section{Key messages}

- Wildlife farming generates significant earnings for many households in many provinces, and creates employment opportunities for the rural workforce.

- The fact that many households in many provinces depend on wildlife farming as their main source of income also creates major challenges for wildlife conservation and management.

- Diversifying and developing sustainable local livelihoods and economic growth are essential for local well-being and for effective wildlife conservation and management. Developing a holistic approach is essential for addressing illegal wildlife trading and ensuring sustainable legal wildlife farming.

- Although research and efforts to document and analyze the economic value of wildlife farming and trading have increased, available data are often outdated and based on small sample sizes from limited numbers of study sites. A well-functioning, transparent and accountable monitoring and evaluation system together with financial support for research on legal and illegal wildlife trading, especially in the context of Covid-19, are essential for effective wildlife conservation in Vietnam.

\section{Background}

Although the illegal wildlife trade is recognized as a global problem, addressing it is hindered by the huge profits it generates. In 2000, trading in wild animals was estimated to be worth more than USD 8 billion worldwide, second only to illegal drug trafficking (Van and Daan 2016). In recent years, this figure has grown to more than USD 20 billion (Broad et al. 2003; Brack 2004; Ferrier 2009; Barber-Meyer 2010; Wilson-Wilde 2010). The European Union and Japan are the largest importers of wildlife from Malaysia, Vietnam, Indonesia and China (Nijman 2010).

Vietnam opened up to international integration in the early 21 st century, thereby making trade in global markets more convenient. Since then, wildlife trade activities have developed significantly in Vietnam

Center for International Forestry Research (CIFOR)

Vietnam National University, Hanoi

3 Nong Lam University
(Nguyen et al. 2008). Vietnam's wildlife trade expansion and growth are apparent from the increase in the number of CITES permits from 594 in 1999 to 2,367 in 2016, and the addition of new wildlife farms since 1980. Although numerous studies have demonstrated the expansion and growth of both legal and illegal wildlife markets, few studies have documented and analyzed the economic importance of these activities in Vietnam. To address this knowledge gap, based on a literature study, this report reviews available data on the financial contributions of the wildlife trade at national, local and household levels, and discusses opportunities for and challenges to managing the trade in Vietnam.

\section{Overview of the wildlife trade in Vietnam}

According to CITES (2017), the provinces of Bac Lieu, Nghe An and Dong Nai have the most breeding facilities in the country, with 2,211, 2,130 and 956 locations respectively. The provinces breeding the highest numbers of wildlife species are Ho Chi Minh City (171), Binh Duong (84) and 
Nghe An (73), mainly for sightseeing and tourism purposes (People and Nature Reconciliation 2020). Wildlife farms are generally commercial enterprises, with common species including leopards, snakes, crocodiles, geckos (lizards), rodents, primates, civets, wild boar, deer and softshell turtles. Approximately $44 \%$ of all species currently traded in markets are listed in CITES (FAO 2015).

Reptiles such as the crocodiles and pythons are easy to keep in captivity, with a total of 716,892 bred in 2013 (FAO 2015). Meanwhile, mammals such as tigers, wildcat and bears can also reproduce in captivity, but detailed information on numbers of individuals born is difficult to obtain (Nguyen et al. 2008). Farms sell to domestic urban bushmeat restaurants serving wealthy families across the country and also supply to international markets (Roberton and Tran 2003). Vietnam's major market in the region is China, with 25 border markets connected by road to the largest commercial ports (Zhang et al. 2008).

The estimated total volume of wildlife and wildlife meat consumed in and exported from Vietnam is around 3,050 tons per year, around half of which is consumed domestically (Nguyen 2003). The wildlife meat trade accounts for $80 \%$ of the total and is concentrated in large cities such as Hanoi and Ho Chi Minh City (Nguyen 2003). The illegal wildlife trade is thought to generate approximately USD 5.3 million annually, which is eight times larger than amounts currently spent on surveillance by the Forest Protection Department (FPD) and other agencies, and state budget allocation for wild life conservation (TRAFFIC 2014).

\section{Contribution of the wildlife trade to the national economy}

Annual revenues and profits from illegal wildlife trading in Vietnam are estimated to be USD 66.5 million and USD 21 million, respectively. For the whole country, total estimated profit is 31 times higher than expenditure (USD 634,000-700,000); more than three times the total budget for FPD staff (around USD 6.5 million); and four times the amount collected in fines (USD 5.5 million) per year (Nguyen 2003). Estimated total annual revenue from illegal trade (USD 66.5 million) is 12 times the total annual revenue from legal trade (USD 5.2 million). According to estimates, only 3.1\% of the total value of the illegal wildlife trade is recouped through confiscation (Nguyen 2003). The illegal wildlife trade in Vietnam generated over USD 43 million in revenues and profits in 2014 (TRAFFIC 2014).

Figures 1 and 2 show the market values of Vietnam's animal exports and imports. Although no specific records or statistics exist on what percentages of total values can be attributed to wildlife imports and exports, many scholars believe the patterns presented in these figures are similar for the wildlife trade.

\section{Contributions of wildlife to provincial economies}

TRAFFIC (2014) reported that wildlife farms employ substantial numbers of farm laborers in Cao Bang, $\mathrm{Ha}$

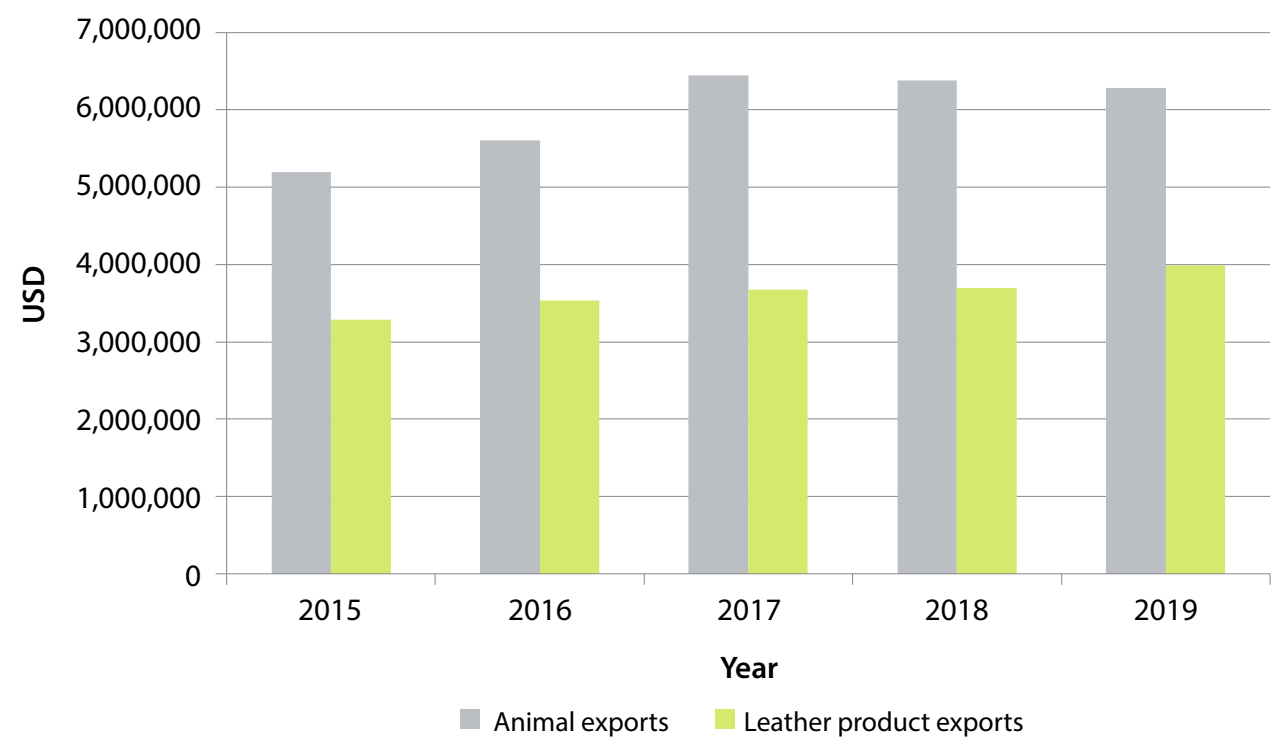

Figure 1. Economic value of Vietnam's animal exports in the 2015-2019 period 


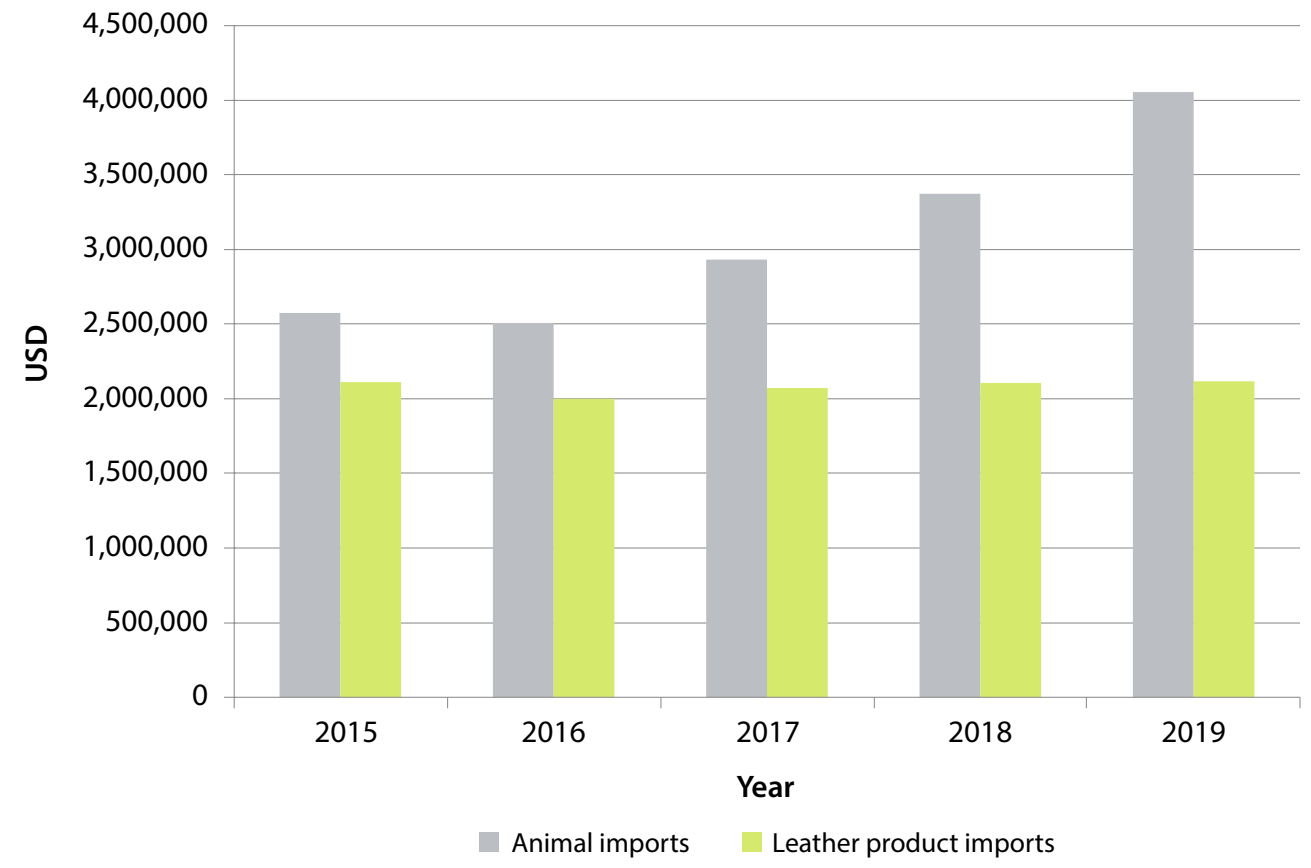

Figure 2. Economic value of Vietnam's animal and animal skin product imports in the 2015-2019 period

Source: World Integrated Trade Solution (WITS) 2021

Giang, Lai Chau, Nghe An, Quang Binh, Kon Tum and Gia Lai provinces. Incomes from wild animal breeding enterprises are higher than those generated from poultry farming or crop cultivation. The working hours devoted to wildlife farming are much lower than those devoted to agricultural activities (Figures 3, 4 and 5).
Crocodile breeding, for example, brought in 15 times more income than rice farming in An Giang and Ca Mau provinces in 2003, whereas rice farming requires twice as many working days as crocodile breeding (Figure 5). Many studies of wildlife farming households in the Red River and North Central regions drew similar conclusions. In the

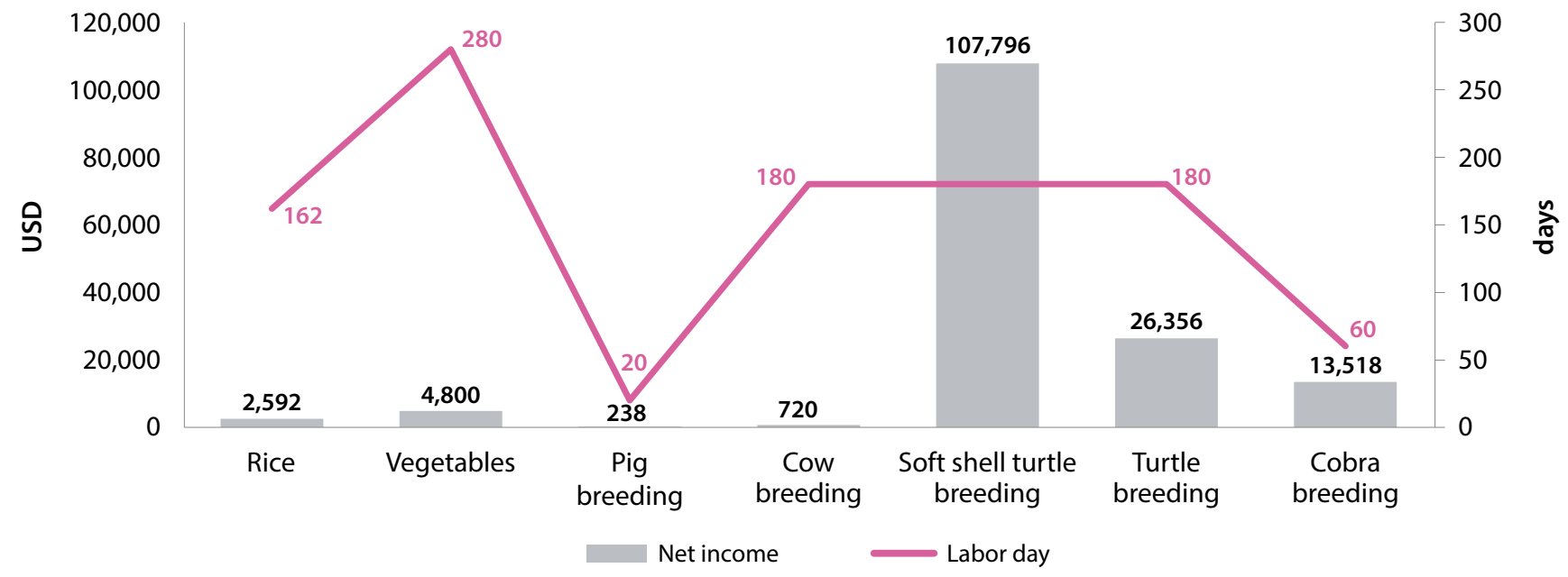

Figure 3. Net income and working days for some farming models in Hai Duong, Ha Tay, Bac Giang and Vinh Phuc provinces in 2003 


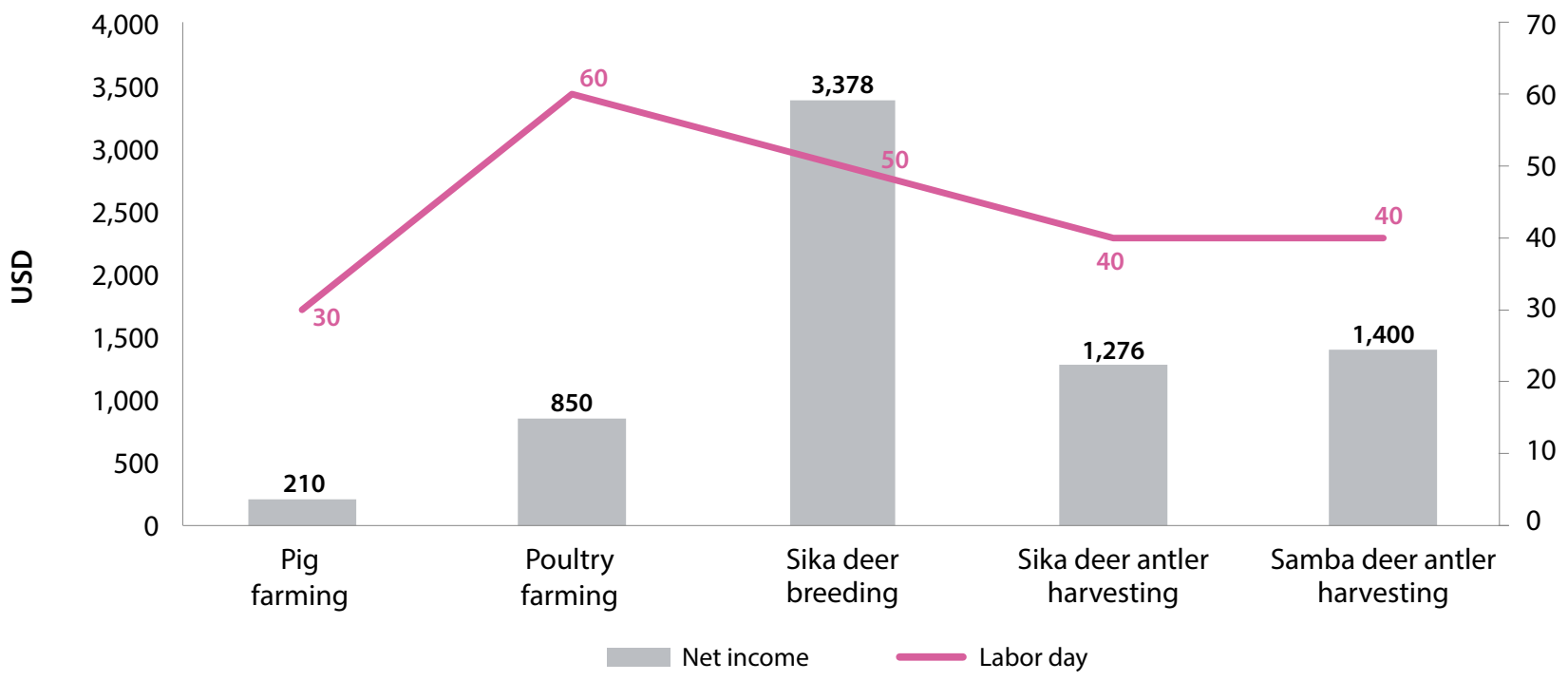

Figure 4. Net income and working days for some animal farming models in Nghe An and Ha Tinh provinces in 2003

Source: Do et al. 2003

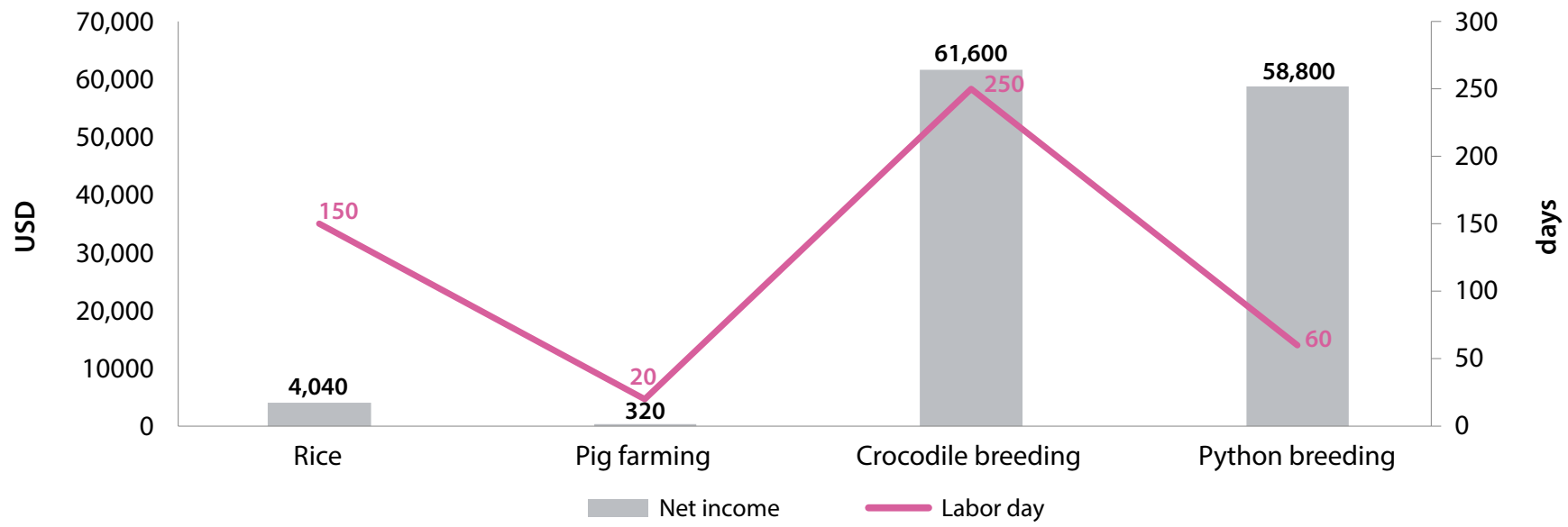

Figure 5. Net income and working days for some farming models in An Giang and Ca Mau provinces in 2003

Source: Do et al. 2003

Red River region, for example, income from snake farming is five times higher than income from growing rice and other crops. In addition, earnings from deer breeding and antler production were 5-10 times higher than those from chicken and pig farming (Nguyen et al. 2008).

According to the Vinh Phuc Provincial Forest Protection Department (2006), revenue from commercial wildlife products in Vinh Son commune in 2006 was approximately USD 465,000 increasing at a rate of 20\% annually. This rate increase is 20 times higher than for growing crops such as rice. According to agriculture statistics in Quynh Luu district, 3,380-15,000 deer were being reared in the area in 2016, at an annual value of approximately USD 696,900-1,306,689. (Nghe An newspaper 2016; Department of Science and Technology of Nghe An province 2017)

\section{Contributions of wild animals to household economies}

Currently, there are 25 million forest-dependent people in Vietnam (World Bank 2005). Wild life farming activities and their associated services have contributed to solving high unemployment rates in some regions and increased incomes for many households in rural areas. Snake farming, 


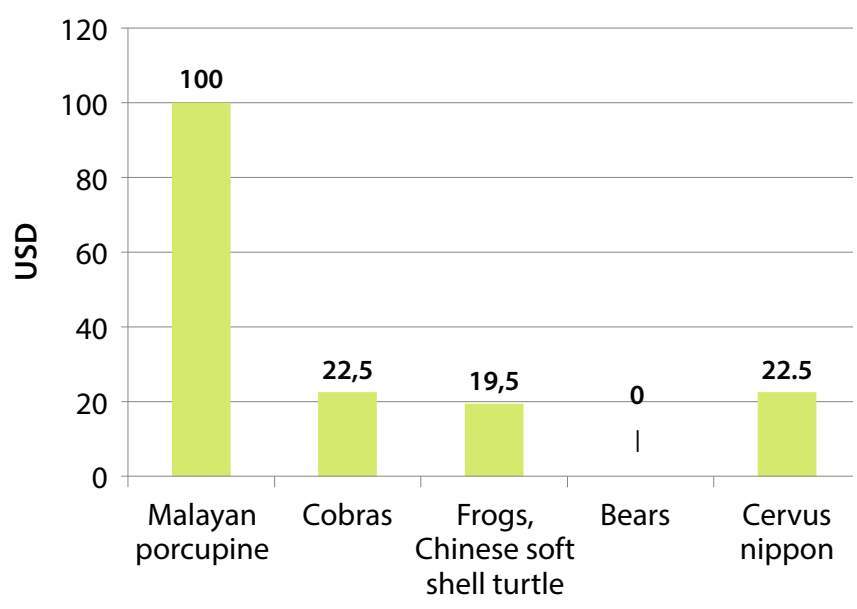

Figure 6. Profits on investments (\%) breeding wild animals in Ho Chi Minh City, Kien Giang, An Giang, Vinh Long, Ha Noi, Ninh Binh, Vinh Phuc, Quang Ninh, Ha Tinh and Son La provinces in 2007

Source: Do et al. 2003

for example, provides an average income of USD 93 a month for each working resident, thereby improving quality of life and helping alleviate poverty in the locality (Nguyen et al. 2008). Further, in some provinces, average per capita incomes from wildlife farming after deducting material costs, taxes and depreciation, and excluding labor, range from USD 87 to USD 168 a month, depending on type, and account for 35\%-37\% of total average household incomes (Nguyen et al. 2008). Wildlife farming is also highly profitable (Figure 6).

\section{Discussion and conclusion}

This policy brief indicates that wildlife farming provides significant economic value to many localities and households, and creates employment opportunities for working people in rural areas. While many conservation organizations expect wildlife farm closures in Vietnam (Eurogroup for Animals 2020; People and Nature Reconciliation 2020), the value of benefits brought from such farms could pose a major obstacle and challenge to implementing this expectation. Creating and diversifying livelihoods for people and ensuring conservation activities do not negatively affect their lives are factors that require careful consideration. This report shows that illegal wildlife trade activities bring in much higher revenues and profits than legal activities from wildlife farming. Consequently, illegal and legal wildlife trade activities should both be addressed simultaneously.

Research and efforts to document and analyze the economic value of wildlife farming and trading have increased, but available data are often outdated and based on small sample sizes from limited numbers of study sites. With Vietnam's commitment to CITES, it is essential to establish an effective monitoring and surveillance system and ensure financial support for research on both the legal and illegal wildlife trade in Vietnam. The Covid-19 pandemic has affected economic activities, including wildlife farming, and changes in stakeholder perceptions and attitudes will also affect trade in this area. Recording and analyzing these changes are essential for effective implementation of wildlife conservation policy in Vietnam.

\section{Acknowledgments}

We would like to thank the CGIAR-COVID Hub, the United States Agency for International Development (USAID), and the CGIAR Research Program on Forests, Trees and Agroforestry (FTA) for supporting this study.

\section{References}

Barber-Meyer SM. 2010. Dealing with the Clandestine Nature of Wildlife-Trade Market Surveys. Conservation Biology, 24(4), 918-23. Accessed 11 July 2021. http://www.jstor.org/ stable/40864190

Nghe An Newspaper. 2016. Antler had been exploited for more than 4 tons in Quynh Luu. Accessed 11 July 2021. Antler had been exploited for more than 4 tons in Quynh Lưu Economic news | Nghe An newspaper (baonghean.vn)

Brack D. 2004. The growth and control of international environmental crime. Environmental health perspectives, 112(2), A80-A81. Accessed 11 July 2021. https://doi. org/10.1289/ehp.112-1241850

Broad S, Mulliken T, Roe D. 2003. The Nature and Extent of Legal and Illegal Trade in Wildlife. The Trade in Wildlife, Regulation for Conservation. Earthscan. Accessed 11 July 2021. https://doi.org/10.4324/9781849773935

[CITES] Convention on International Trade in Endangered Species of Wild Fauna and Flora. 1999. Annual report of CITES export, import and re-export of 1999. Hanoi, Vietnam. Accessed 11 July 2021. https://ec.europa.eu/environment/ cites/pdf/reports/1999_annual.pdf

[CITES] Convention on International Trade in Endangered Species of Wild Fauna and Flora. 2016. Annual report of CITES export, import and re-export of 2016. Hanoi, Vietnam. Accessed 11 July 2021. https://ec.europa.eu/environment/ cites/pdf/reports/2016 annua.pdf

Web portal, Department of Science and Technology of Nghe An province. 2017. Quynh Luu applies scientific and technological advances in all fields of economic development. Accessed 11 July 2021. Quynh Luu applies scientific and technological advances in all fields of economic development | Scientific research | Department of Science and Technology (ngheandost.do.vn) 
Do KC, Vu VD, Nguyen TT. 2003. Economic incentive as a solution to strengthen wildlife trade management in Vietnam. Report to FPD, MARD and TRAFFIC Southeast Asia, Hanoi, Vietnam.

Eurogroup for Animals. 2020. Coronavirus: NGOs ask governments to shut down wildlife markets and work to reduce demand. Accessed 11 July 2021. https://www. eurogroupforanimals.org/news/coronavirus-ngos-askgovernments-shut-down-wildlife-markets-and-workreduce-demand.

[FAO] Food and Agriculture Organization of the United Nations. 2015. Background on wild animals in Vietnam: A brief report on a pilot update of wildlife farms data in southern Vietnam. Accessed 11 July 2021. http://www.fao. org/fileadmin/user_upload/FAO-countries/Vietnam/docs/ Pdf_files/FINAL_wildlife_farm_factsheet_VN.pdf

Nguyen VS. 2003. Wildlife trading in Vietnam: Why it flourishes. Research Report. Economics and Rural Development Faculty. Hanoi Agricultural University, Vietnam. Accessed 11 July 2021. http://hdl.handle.net/10625/46082

Nguyen MH, Vu VD, Nguyen VS, Hoàng VT, Nguyen HD, Pham NT, Tran TH, Đoang C. 2008. Report on the review of Vietnam's wildlife trade policy. CRES/FPD/UNEP/CITES/ IUED. Accessed 11 July 2021. https://cites.org/sites/ default/files/common/prog/policy/Vietnam_wildlife_ trade_policy_review.pdf

Nijman V. 2010. An overview of international wildlife trade from Southeast Asia. Biodivers Conserv, 19, 1101-1114. Accessed 11 July 2021. https://doi.org/10.1007/s10531009-9758-4
Roberton SI, Tran T, Momberg F. 2003. Hunting and Trading Wildlife: An Investigation into the Wildlife Trade in and around the Pu Mat National Park, Nghe An Province, Vietnam. Nghe An: SFNC Project Management Unit. Accessed 11 July 2021. https://cres.vnu.edu.vn/iu-tra-tinh-hinh-khai-thac-vabuon-ban-ng-vt-hoang-da-ti-vi-quc-gia-pu-mat-ngh-an/

TRAFFIC. 2014. Accessed 11 July 2021. http://www.traffic. org/campaigns/

People and nature Reconciliation. 2020. Vietnam considers wildlife trade ban in response to coronavirus pandemic. Accessed 11 July 2021. https://www.nature.org.vn/ en/2020/03/vietnam-considers-wildlife-trade-ban-inresponse-to-coronavirus-pandemic/

[WCS] Wildlife Conservation Society. 2008. Commercial wildlife farms in Vietnam: A problem or solution for conservation. Wildlife Conservation Society. Accessed 11 July 2021. https://programs.wcs.org/beta/Resources/ Publications/Publications-Search-II/ctl/view/mid/13340/ pubid/DMX3329600000.aspx

Wilson-Wilde L. 2010. Wildlife crime: A global problem. Forensic Sci Med Pathol, 6(3), 221-222. Accessed 11 July 2021. https://doi.org/10.1007/s12024-010-9167-8

World Bank. 2005. Vietnam Environment Monitor. Accessed 11 July 2021. https://www.worldbank.org/en/home

[WITS] World Integrated Trade Solution. 2021. Accessed 11 July 2021. https://wits.worldbank.org/

Zhang L, Hua N, Sun S. 2008. Wildlife trade, consumption and conservation awareness in southwest China. Biodivers Conserv 17, 1493-1516. Accessed 11 July 2021. https://doi. org/10.1007/s10531-008-9358-8

\begin{tabular}{|l|ll} 
RESEARCH & $\begin{array}{l}\text { The CGIAR Research Program on Forests, Trees and Agroforestry (FTA) is the world's largest research } \\
\text { for development program to enhance the role of forests, trees and agroforestry in sustainable } \\
\text { development and food security and to address climate change. CIFOR leads FTA in partnership with } \\
\text { PROGRAM on }\end{array}$ \\
$\begin{array}{l}\text { Forests, Trees and } \\
\text { Agroforsity International, CATIE, CIRAD, ICRAF, INBAR and TBI. }\end{array}$
\end{tabular}
FTA's work is supported by the CGIAR Trust Fund: cgiar.org/funders/

\section{USAID}

